\title{
Cultural intelligence and institutional success: The mediating role of relationship quality
}

\begin{abstract}
As managerial rationality is always bounded, managers utilise their cognitive abilities and social relations to manage their operational environmental uncertainties. We posit that relationship quality (RQ) mediates the association between cultural intelligence (CQ) and success in managing challenges arising out of differences in the institutional environments i.e. institutional success. Our CQ measure comprises cognitive, metacognitive, motivational and behavioural CQs. We included the interactive effects of two inter-related mental capabilities, namely cognitive and metacognitive CQs, and motivational and behavioural CQs while examining the mediating role of RQ between CQ and institutional success. Based on data from 186 Indian senior managers doing business with New Zealand, we find mixed support for our hypotheses. We find indirect-only mediation effects for interactive effects of cognitive and metacognitive CQs, and complementary mediation effects for motivational CQ. Contrary to expectations, we find negative direct-only non-mediation effects of behavioural CQ.
\end{abstract}

Key words: Cultural intelligence, business relationship quality, institutional success, India, New Zealand

\section{Please cite this paper as follows}

Sharma, R. R. (2019). Cultural intelligence and institutional success: The mediating role of relationship quality Journal of International Management, 25(3) doi: https://doi.org/10.1016/j.intman.2019.01.002 


\section{Introduction}

Challenges arising out of cultural and regulatory differences, and environmental risks and uncertainties are fundamental to an international business activity (Aharoni, Tihanyi and Connelly, 2011). Dealing with such institutional environmental dynamism and challenges consumes a significant share of senior managers' time and is a critical factor for success and failure (Henisz \& Swaminathan, 2008). The difference in institutional environments may result in negative organisational outcomes because of the increase in uncertainty and transaction costs (Trąpczyński and Banalieva, 2016). The institutional theory suggests that though managers have bounded rationality, their interactions with institutions guide their acceptable behaviour and thus reduce uncertainty (Peng, 2002). Kostova, Roth and Dacin (2008), further argue that the institutional environments are country specific and dynamic and that they constantly evolve within the social economic environments of a country and shape managerial actions. Thus, managers must make sense of how to effectively operate in, and even construct their institutional environments.

We focus on the role of cultural intelligence (CQ) and relationship quality in managing challenges arising out of differences in the institutional environments they operate in, defined as institutional success in this study. In complex institutional environments managers make their boundedly rational decisions utilising their cognitive abilities and social relations (Aharoni, 1966). The role of CQ in achieving positive outcomes in unfamiliar business environments is widely accepted (Ott and Michailova, 2018; Rockstuhl and Van Dyne, 2018). As decision making is based on managerial perceptions and not just hard objective facts, such perceptions with respect to the strategic tools used (e.g. relationship quality) or outcomes achieved (e.g. institutional success) are gaining recent attention (Aharoni et al., 2011).

Based on a survey of 1000 senior managers across 28 countries, Rosen et al. (2000) stress the role of global literacy (including cultural literacy) as the increasing economic 
integration implies the increasing importance of cultural differences. Similarly, Hutchings (2003) finds negligible organisational training for Australian expatriates in China on cross cultural preparations. The need to understand the impact of cultural diversity on management behaviour is crucial as human aspects are gaining more importance, thanks to the knowledgebased competitive environment (Doz, Santos and Williamson, 2001). Given the increased global connectivity and cross border interactions and the diversity in international environments, CQ allows managers to meet the challenges posed by the complex, not-so-flat global environment (Ashkenas et al., 2002). CQ allows managers to think outside their narrow cultural boundaries and decode complex cross cultural interactions (Andresen and Bergdolt, 2017).

Rockstuhl and Van Dyne's (2018) recent meta-analysis of CQ literature examined direct, mediating and interactive effects of $\mathrm{CQ}$ facets. In their future research recommendations, they made a call to "replicate and extend interactive CQ effects" (p. 138) using primary data. Both Chua and Ng (2017 p.294) and Rockstuhl and Van Dyne (2018 p.128) cited Gelfand, Imai and Fehr (2008) in highlighting the need to understand interactive effects of CQ facets on an outcome. The theory of multiple intelligences, developed by psychologist Howard Gardner, argues that individuals possess a number of relatively autonomous intelligences which influence them individually as well as collectively (Davis et al., 2011). Rockstuhl and Van Dyne (2018) noted that "they are aware of only one study (Chua and $\mathrm{Ng}$, 2017) that has examined interactive effects of CQ factors" (p. 128).

We included the interactive effects of two inter-related mental capabilities, namely cognitive and metacognitive CQs, and motivational and behavioural CQs while examining the mediating role of quality of relationships of global managers with their overseas business partners (hereafter called relationship quality) between CQ and institutional success. The need 
to examine the mediating effects of relationship quality (RQ) is also called for by Rockstuhl and Van Dyne (2018 p.137).

The role of RQ is well established in the literature (Elfenbein and Zenger, 2014; Lahiri and Kedia, 2011; Leonidou et al., 2014; Raman et al., 2013). The widely accepted view is that it is helpful in getting positive outcomes though there could be challenges or dark sides to such relationships (Anderson and Jap, 2005). We posit that when your business partners are from other cultures, CQ enhances the quality of such relationships. Institutional differences may create challenges and complexity in terms of communication, coordination and agreeing on mutually accepted managerial approaches (Ho, Ghauri and Larimo, 2018). CQ helps to address such challenges successfully as it enables managers to manage their anxiety and uncertainty in unfamiliar environments (Gudykunst, 2005; Malek and Budhwar, 2013). We propose that CQ facets enhance RQ which in turn results in institutional success.

The proposed hypotheses are tested based on the experiences of 186 Indian senior business managers doing business with New Zealand. The pair of countries chosen is mainly because of the nature of the external grant which funded this research project. The chosen two countries represent an appropriate setting because of the differences in institutional environments between the two countries (see section 4.1). The key findings suggest that RQ has indirect-only mediation effects on the association between interactive effects of cognitive and metacognitive CQs, and institutional success. It has complementary mediation effects for motivational CQ. Contrary to expectations, the study finds direct-only non-mediation negative effects of behavioural CQ.

By examining mechanisms (mediation effects of relationship quality) and boundary conditions (interactive effects of two mental CQ capabilities), we contribute by enhancing the understanding of how $\mathrm{CQ}$ results in institutional success. We also contribute to the emerging 
economies literature by providing understanding of how Indian senior managers utilise CQ and RQ to achieve institutional success while operating in an advanced economy.

The rest of the paper is organised as follows. The next section reviews the literature and is followed by a section on hypotheses development. Then we describe research methods and data. The following section presents results. The last section concludes the paper and presents the discussion, implications and limitations of the study.

\section{Literature Review}

\subsection{Cultural intelligence}

Ang et al. (2007) build on Earley and Ang (2003) and Earley and Mosakowski (2004) to define CQ as "a specific form of intelligence focussed on capabilities to grasp, reason and behave effectively" in culturally diverse situations (p.337). Similarly Thomas et al. (2015) define CQ as the ability to "interact effectively with culturally different individuals" (p. 1100). Both Ang et al. (2007) and Thomas et al. (2015) see CQ as individual differences that explain cross cultural effectiveness, wherein CQ is a culture-independent and multidimensional construct. The development of CQ is not tied to a culture and it can be developed in one culture and applied in another.

CQ is not the same as general intelligence (IQ) or emotional intelligence (EQ). IQ is "the ability to grasp reason correctly with abstractions (concepts) and solve problems" (Schmidt and Hunter, 2000 p. 3). EQ on the other hand is the ability to express, regulate and utilise emotions in decision making (Salovey and Mayer, 1990). It is the ability to understand and deal with personal emotions. Earley and Mosakowski (2004) argue that CQ "picks up where EQ leaves off' (p.139). They cited an example of American and German managers to illustrate differences between CQ and EQ. While working together, German managers condemned harshly any ideas the team was putting forward. The American manager, 
perceiving Germans as rude and aggressive and being empathetic (high EQ), proposed a new discussion style while ignoring that the merit of the idea and the person are not the same for Germans; which a manager with high CQ would have imagined. EQ and IQ are culture bound emic constructs as emotions are constructed and transmitted within cultures (Fitch, 1998; $\mathrm{Ng}$ and Earley, 2006). CQ on the other hand is culture free etic construct. It is a 'general set of capacities' for culturally diverse situations. CQ is moderately related but distinct from EQ (Thomas et al., 2015).

CQ has been measured as a second order multidimensional construct (Thomas et al., 2008; Thomas et al., 2015) as well as an aggregate multidimensional construct where dimensions may or may not correlate with each other (Ang et al., 2007; Earley and Mosakowski, 2004). According to Thomas et al. (2008) CQ is "a system of interacting knowledge and skills linked by cultural metacognition that allows people to adopt, select, and shape the cultural aspects of their environment" (p.126). The effectiveness of gaining knowledge and skills in one cultural setting and applying them in another context depends upon the metacognition ability of the individual.

Building on Earley and Ang (2003) and Earley and Mosakowski (2004), Ang et al. (2007) developed and validated a multidimensional CQ construct which includes four dimensions of CQ: metacognitive, cognitive, motivational and behavioural. This construct is based on the theory of multiple intelligences (Sternberg, 1985) which argues that there are different 'loci' of intelligence within each person. Cognitive CQ "reflects knowledge of the norms, practices and conventions" while metacognitive CQ "reflects mental processes to acquire and understand cultural knowledge" (Ang et al., 2007 p.338). Motivational CQ is the mental capacity to effectively utilise energy which is critical to problem solving in the real world (Ceci, 1996). Ang et al. (2007 p.338) define it as the ability "to direct attention and energy towards learning'" in culturally diverse settings. The fourth dimension of behavioural 
CQ relates to individuals' actions rather than their thinking. It reflects their "capability to exhibit appropriate verbal and non-verbal actions" in cross cultural settings (Ang et al., 2007 p.338).

\subsection{Cultural intelligence and managerial outcomes}

Navigating cultural differences in management behaviour has become a critical skill in today's globally integrated, knowledge-based, competitive environment (Thomas, 2017). In a recent literature review, Ott and Michailova (2018) noted three main themes for examining the impact of CQ: adjustment and adaptation, performance and effectiveness and cross cultural leadership. Among these categories, CQ has been examined as the main independent variable as well as a mediator or moderator.

Findings in the literature regarding the impact on adjustment and adaptation, though generally positive, do show some inconsistencies (Ott and Michailova, 2018). Ang et al. (2007) find a positive impact of metacognitive and cognitive CQ on cultural adjustment and decision making and motivational and behavioural CQ on cultural adaptation. They also find a positive impact of metacognitive and cognitive CQ on task performance while no such evidence was found for motivational and behavioural CQ. Cognitive and metacognitive CQ involves information processing, reasoning, thought processes, and analysis of information which helps in cultural decision making and task performance. Motivational and behavioural CQ on the other hand involve a higher intrinsic interest with the ability to adjust behaviour leading to cultural adaptation. CQ has also been found to influence job performance, communication effectiveness, cross cultural negotiations, multicultural team performance, and intention to work abroad (Bücker et al., 2014; Groves, Feyerherm and Gu, 2015; Peng, Van Dyne and Oh, 2015). 
CQ also improves cross cultural leadership effectiveness. In a study of 126 Swiss military officers with leadership responsibilities, Rockstuhl et al. (2011) find CQ to be a stronger predictor of cross border leadership effectiveness as compared to IQ and EQ. In this study IQ predicted effectiveness in both domestic and global leadership, while EQ was stronger only in domestic leadership effectiveness. It implies that individuals who are effective in domestic contexts may not be effective in cross border settings. They argue that the stronger impact of CQ for cross border leadership effectiveness is because of their awareness, judgement suspension, behaviour adaptability and exclusionary reactions. Individuals with cross cultural awareness understand the impact of their own culture and background vis a vis others' culture and backgrounds. They pause and verify their cultural assumptions before reaching to conclusions. Because of their motivation and behavioural flexibility they understand self and others and adapt their leadership behaviour. They are likely to develop trust with culturally unlike and are less likely to engage in exclusionary reactions. The exclusionary reactions occur because individuals view other individuals from perceptually different groups as members of the outgroup (Tajfel, 1981; Turner, 1987).

Cultural exposure has been found to enhance CQ as it allows individuals to experience diverse cultures and learn from such experiences. This enhances their open-mindedness, cultural empathy, emotional stability and flexibility (Crowne, 2013). Prior international contact provides opportunities to enrich CQ by developing cross cultural skills, facilitating flexibility, strengthening motivation, and adjusting mental modes in cross-cultural interactions (Deal et al., 2001). Prior intercultural contact leads to global leadership effectiveness by enhancing the CQ of the majority status leaders (Kim and Van Dyne, 2012). Majority or minority status depends on the country of origin. For example, U.S. origin leaders in the U.S. are majority status leaders as compared to the leaders in the U.S. with non U.S. origin. Full mediation effects are found for majority and no mediation is found for minority status managers. As majority 
(e.g. U.S. origin in the U.S.) will have fewer intercultural contacts than minority, such intercultural contacts are more beneficial for the majority. Thus, CQ is critical for the success of majority status managers seeking global positions. Low CQ global managers engage in stereotyping which results in conflicts and failures (Manning, 2003).

Global managers' cross cultural competence also depends on their perception, relationship and self-management (Bird et al., 2010). Perception management is achieved by being non-judgemental, inquisitive, tolerant of ambiguity, cosmopolitan and inclusive. Relationship management is enhanced by value in relationships, interpersonal engagement, emotional sensitivity, self-awareness, and social flexibility. Finally, the self-management element includes optimism, self-confidence, self-identity, emotional resilience, non-stress tendency, stress management, and interest flexibility. Perception, relationship and selfmanagement of individuals depend on their CQ.

Only a few studies have focussed on the impact of CQ on cross cultural relationship enhancement (Ott and Michailova, 2018). Groves et al. (2015) posit that CQ results in favourable negotiations as it helps behavioural adaptation in cross cultural settings. Managers' skills in understanding cultural assumptions help them to develop trust while collaborating across cultures (Chua, Morris and Mor, 2012), and result in intercultural coordination and cooperation (Mor, Morris and Joh, 2013). CQ is also found to reduce anxiety in cross cultural interactions and thus result in communication effectiveness.

Rockstuhl and Van Dyne's (2018) meta-analysis of 167 CQ studies with 199 distinct samples with a combined sample size of 44155 respondents reported direct, interactive, and mediation effects for CQ facets with mixed results for their hypotheses (see the paper for details). They called to examine CQ factors' specific outcomes, interactive effects and boundary conditions of CQ facets (p.138). 
Based on the above literature review, it can be argued that CQ contributes to positive organizational outcomes in general. CQ also helps to foster effective intercultural collaborations. The literature also points at the role of RQ in managing institutional challenges in complex environments (Aharoni et al., 2011; Peng, 2002). However, how CQ facets interactively influence an outcome is not well understood (Rockstuhl and Van Dyne, 2018). Moreover, given the institutional dynamism, challenges and their unintended consequences (Henisz and Swaminathan, 2008; Kostova et al., 2008), global managers need to manage institutional challenges. Accordingly, the next section focuses on and builds arguments for the hypothesised relationships between CQ, RQ and institutional success.

\section{Hypothesis development}

The main endogenous variable studied is the institutional success i.e. perceived success in managing challenges arising out of institutional differences. The differences in institutional profiles matter for doing business in cross institutional settings. Such differences can create misunderstandings and legitimacy problems (Denk, Kaufmann and Roesch, 2012). As such differences increase, their management becomes more challenging (Trąpczyński and Banalieva, 2016; Van Hoorn and Maseland, 2016). The differences in institutional environment may arise on account of differences in rules, laws, regulations, cultural values, norms, ethical practices and overall business environment. Moreover, institutions constantly evolve and may influence and be influenced by managerial actions (Kostova et al., 2008).

Relationship quality is another outcome variable of interest (mediating variable) which has been defined as the extent of stable and healthy relationships between exchange partners (Jiang et al., 2016) and exchange partners' overall assessment of their ongoing business relationships (Lahiri and Kedia, 2011). We define RQ as business managers' overall assessment of their quality of relationships with their overseas business partners. 


\subsection{Direct effects of cultural intelligence}

The four CQ dimensions examined in this study include cognitive, metacognitive, motivational and behavioural dimensions (Ang et al., 2007; Earley and Mosakowski, 2004). Managers with high cognitive CQ are more likely to have a broader knowledge of foreign political, social, cultural and economic systems (Ang et al., 2007; Earley and Ang, 2003; Schlägel and Sarstedt, 2016). Metacognitive CQ, on the other hand, relates to the mental processes of acquiring and understanding knowledge of the norms, practices and conventions of other cultures (Ang et al., 2007). Metacognitive CQ is also called thinking about thinking. Brislin, Worthley and Macnab (2006) argue that metacognitive CQ individuals are consciously aware of others' cultural preferences, question cultural assumptions and adjust their mental modes through knowledge and control of their thought processes. It is higher order knowledge and is goes further than merely understanding similarities and differences across economic, political and cultural environments.

Understanding cultural differences and preferences of business partners from other cultures (cognitive CQ) is likely to enhance mutual understanding and trust between exchange partners. However, just having cultural knowledge may not be enough to achieve an outcome, rather it would need to be accompanied by metacognitive CQ to make better sense and use of cultural knowledge and have an enhanced outcome (Chua and Ng, 2017; Rockstuhl and Van Dyne, 2018). Cognitive CQ may even result in negative outcomes because of 'sophisticated stereotyping' which Osland and Bird (2000) define as reducing "a complex culture to a shorthand description" (p.66) and applying it to all people in that culture. Metacognitive CQ dampens this negative effect of stereotyping others based on cultural knowledge because those with high metacognitive CQ should be more likely to actively check their assumptions and suspend judgment in intercultural contexts. 
In a study of creativity in a global context Chua and $\mathrm{Ng}$ (2017) argued that it is not just how much you know (cognitive CQ) which impacts creativity, but it also depends on your metacognitive capability. They find that for low metacognitive individuals the impact of cognitive CQ is inverted U-shaped. They did not find a significant effect of cognitive CQ for high metacognitive individuals. Similarly Rockstuhl and Van Dyne (2018) also find the interactive effects of cognitive and metacognitive CQs on intercultural effectiveness. Cognitive and metacognitive CQs are two inter-related capabilities which have an interactional effect on an outcome. Towing this line, we propose that the interactive effects of cognitive and metacognitive CQs will enhance the two outcomes of RQ and institutional success. In other words, we propose that the effect of cognitive CQ will be stronger for high metacognitive business partners.

High metacognitive individuals are found to be more effective in intercultural collaborations (Chua et al., 2012), task performance, cultural judgement, decision making effectiveness (Ang et al., 2007), and intercultural cooperation (Mor et al., 2013). Such individuals develop trust in intercultural relationships and cooperation because of cultural perspective taking. Cultural perspective taking means understanding the impact of others' cultural background on their responses. Individuals with high metacognitive CQ engage in effective self-regulatory processes, such as awareness and checking, and thus are able to reduce the unintended effects of cultural knowledge and make better use of cultural knowledge (Van Dyne et al., 2012). Awareness about cultural assumptions and contexts contribute to a better use of cultural knowledge, while checking enables critical evaluation and using cultural knowledge.

When cultural knowledge (cognitive CQ) is accompanied by contextualised thinking and cognitive flexibility (metacognitive CQ), it is likely to help individuals make better use of cultural knowledge and thus create a better outcome. Contextualised thinking implies that 
cultural context shapes individuals' thoughts and actions. Cognitive flexibility on the other hand implies flexibility in the use of one's own knowledge and behaviour in cross cultural settings. Individuals with higher cognitive and metacognitive abilities are less likely to behave ethnocentrically (Triandis, 2006). This is because they can make an effective interpretation of intercultural interactions from others' perspectives with a deeper sense of culturally conditioned alternative behaviour (Ang et al., 2007). Thus, knowledge about business partners' culture, cognitive flexibility and contextualised thinking enhances the quality of relationships with business partners from other cultures. Higher levels of knowledge including contextualised thinking and cognitive flexibility enable managers to avoid stereotypes about the regulatory, cultural and ethical environment. Thus, they are able to manage challenges arising from institutional differences.

The third dimension of CQ, motivational CQ is the ability to effectively utilise attention and energy in solving problems in culturally diverse settings (Ang et al., 2007; Ceci, 1996). High motivational CQ individuals have an intrinsic interest in and confidence to achieve effectiveness in culturally diverse situations (Bandura, 2002).

Ang et al. (2007) find significant support for the impact of motivational CQ on cultural adaptation. They argue that operating in unfamiliar cultural environments is stressful because of differences in norms and behaviours. Motivational CQ helps in adapting to other cultures and reducing cross cultural anxiety. Motivational CQ individuals have intrinsic motivation and cultural self-efficacy. This results in cross cultural learning experiences, leading to their effective adjustment in cross cultural settings (Peng et al., 2015). Cultural self-efficacy implies self-assessment as to the capability of succeeding in a culturally diverse environment (Bandura, 2002; Templer, Tay and Chandrasekar, 2006). Such individuals value cultural experiences and enjoy interacting with people from diverse backgrounds. For the same reason such managers will be conscious about institutional differences in terms of differences in regulations, culture, 
norms, ethics and will thus be able to manage them effectively. Because of their intrinsic motivation and self-efficacy, managers get motivation and confidence to manage challenges that arise because of institutional environmental differences. Rockstuhl and Van Dyne (2018) also find motivational $\mathrm{CQ}$ is positively associated with socio-cultural adjustment and psychological wellbeing. They also find that it is positively associated with leadership performance.

The last dimension of CQ, behavioural CQ, deals with enabling appropriate verbal and nonverbal behaviour considering the differences in institutional environments (Ang et al., 2007). These situationally appropriate behaviours are likely to meet others' expectations and thus reduce misunderstandings. Some research supports the positive effects of behavioural flexibility on performance in cross cultural settings (Shaffer et al., 2006).

In summary, CQ results in gaining legitimacy in the foreign institutional environment because of an enhanced knowledge and deep understanding of the environment, a 'can do' approach and conformity to norms, values and expectations of the institutional environment. Based on the above discussion we hypothesise that:

Hypothesis 1a: Cognitive CQ when accompanied by metacognitive CQ contributes positively to (i) relationship quality, and (ii) institutional success.

Hypothesis 1b: Motivational CQ contributes positively to (i) relationship quality, and (ii) institutional success.

Hypothesis 1c: Behavioural CQ contributes positively to (i) relationship quality, and (ii) institutional success.

\subsection{The mediating role of relationship quality}

In examining the mediating role of RQ, we argue for three relationships: 1) how CQ enhances RQ, 2) how RQ contributes to institutional success, and 3) how RQ acts as a mechanism in 
transforming CQ to institutional success. In the previous section, we have argued and hypothesized that CQ contributes positively to RQ. In summary, we argued that managers with high CQ are more aware, suspend their judgements, adapt behaviour and are less likely to engage in exclusionary reactions (Rockstuhl et al., 2011). Past research also highlights the positive impact of CQ on various aspects of intercultural interactions such as cooperation (Mor et al., 2013), negotiations (Groves et al., 2015) and collaborations (Chua et al., 2012).

In terms of the impact of RQ on an outcome, relationships with business partners have been found to be a critical factor in enhancing performance (Jiang et al., 2016; Sharma, Chadee and Roxas, 2016). The resultant combination of resources and capabilities helps to reduce transaction costs and increase efficiency (Dyer and Singh, 1998). The impact of relationships has been found to result in an 8.5\% increase in willingness to pay (Elfenbein and Zenger, 2014 p.237) and an increase in the value of mutual ventures by at least $15 \%$ (Enlow and Ertel, 2006). Moreover, they lead to positive outcomes in unfamiliar environments as business partners become a good source of learning (Yu and Sharma, 2016).

However, close relationships may also result in raising annoying issues, generating conflicts, and unreasonable expectations (Anderson and Jap, 2005). Knowing each other well puts exchange partners in a position where they feel comfortable to raise any issues. They also learn what the other knows and thus become less dependent. Thus there is a need to be aware of other partners' behaviours, in particular when exchange partners are from other cultures where their behaviour may be confounded by cultural differences. Leonidou et al. (2014) suggest that reducing opportunistic behaviour and conflicts, enhancing communication effectiveness, managing cultural distance and adaptation build quality relationships. Thus, the working environment needs to be understood and managed to enhance the quality of relationships. 
In their meta-analysis, Leonidou et al. (2014) argue that as diverse and dynamic institutional environments result in increased complexity, uncertainty and risk in task executions, quality relationships with business partners in cross border interactions help to manage such challenges. Further, CQ being a set of learning capabilities helps achieve cross cultural effectiveness through managerial learning experiences (Ng, Can Dyne and Ang, 2009) and effective knowledge sharing (Ho et al., 2018). A lack of awareness results in anxiety and uncertainty (Gudykunst, 2005). Environmental dynamism and differences enhance such anxiety and uncertainty (Kostova et al., 2008). RQ fills gaps in cognitive assessments and abilities, and thus helps to overcome institutional challenges (Aharoni et al., 2011). The knowledge gained through business partners reduces such uncertainty, helps manage institutional differences, and thus leads to institutional success.

Considering the significance of relationships and the potential role of $\mathrm{CQ}$ in enhancing relationships, we hypothesise that:

Hypothesis 2: Relationship quality mediates the association between the CQ facets and institutional success.

The proposed model is shown in figure 1 . The model is analysed at the individual level as senior managers' rate questions on their cultural intelligence, quality of relationships with their local business partner and success in managing institutional challenges. Thus, individual level control variables are incorporated in the model. The model controls for age, education, languages ability and international experience of the participating managers. Bernerth and Aguinis (2016) suggest including control variables if they have theoretical relationships with predictors and criteria and can be reliably measured. The selected control variables indicate enhanced learning and thus are likely to influence CQ, RQ and institutional success (Crowne, 2013; Ng et al., 2009).

*Figure 1 about here* 


\section{Methodology}

\subsection{Data and context}

The data to test the proposed model comes from Indian senior business managers doing business with New Zealand. We acquired the contact details of these managers from Kompass India. The data consisted of 918 Indian firms doing business with New Zealand. We focused on three cities namely Bangalore (South), Mumbai (West) and the National Capital Region (North) which hosted 434 of the firms. This constitutes the sampling frame for the study.

We hired an experienced professional to drop and collect surveys from the given list of firms. The drop and collect method has been found to be effective in securing acceptable response rates, in particular in developing economies (Ibeh, Brock and Zhou, 2004). The target respondents were Indian senior executives who had at least two years of experience of doing business with New Zealand. To ensure that the survey was filled out by appropriate managers, we asked the hired professional to collect the business cards of the respondents. We also made random phone calls to some managers for the same reason. In total we received 198 surveys, one response per firm, out of which 186 were found fully usable resulting in a response rate of 42.86\%. Table 1 presents characteristics of the participating managers. The sample is fairly spread for age, education, languages known and international experience.

\section{*Table 1 about here ${ }^{*}$}

The context of India-New Zealand business environment differences fits with the proposed model aiming to examine the impact of cultural intelligence and relationship quality in managing challenges arising out of institutional differences between the two countries. Despite the similarities of having colonial background, using of English as a business language and the democratic nature of countries, both countries differ in terms of some of the cultural dimensions such as power distance, individualism, pragmatism and indulgence (Hofstede, Hofstede and Mincov, 2010). Compared to New Zealand, India has a high power distance, and 
is more collectivist, less pragmatic and a more restrained society. In terms of the ease of doing business, New Zealand ranks much higher as compared to doing business in India (World Bank, 2014). Similarly, New Zealand's human development is much higher and perceived corruption much lower as compared to India (CPI, 2014; UNDP, 2014). On all the governance indicators (voice and accountability, political stability and absence of violence, government effectiveness, regulatory quality, rule of law and control of corruption) New Zealand ranks much higher than India (Kaufmann, Kraay and Mastruzzi, 2015). Such differences highlight the need to understand and navigate through them successfully by avoiding any misunderstanding or mismanagement.

\subsection{Measurement of variables}

Measurement items for each of the main variables of interest are borrowed from established literature and are shown in Table 2. The cultural intelligence constructs are borrowed from Ang et al. (2007). The respondents were asked to read the statements and select the response that best describes them as they are. In line with Lahiri and Kedia (2011), relationship quality is measured as Indian manager's overall assessment of their ongoing relationships with New Zealand business partners. The items included represent trust, commitment, communication and long term orientation (Lages, Lages and Lagesc, 2005; Lages, Lancastre and Lages, 2008; Leonidou et al., 2014). Respondents were asked to rate these items for their relationships with their major business partner in New Zealand. Items to measure institutional success represent differences in the nature and enforcement of rules, laws, and regulations, cultural values, beliefs and norms and ethical business practices which represent typical elements of the institutional environment. These items represent both formal and informal institutions (North, 1990; Peng, Wang and Jiang, 2008). Respondents were asked to rate, based on their overall experience, their success in managing these differences. Among the control variables, age and international 
experience are measured in years. Education is a dummy variable with 0 being undergraduate and 1 postgraduate and above. Languages control variable is measured as the number of languages known by the respondents.

\subsection{Common method bias}

As all the main variables of interest are perceptual in nature, the threat of common method bias (CMB) needs to be addressed using both procedural and statistical remedies (Chang, Witteloostuijn and Eden, 2010; Podsakoff, macKenzie and Lee, 2003). Among the procedural remedies, we assured respondents of the confidentiality of their responses. We also assured them that no answers were right or wrong and encouraged them to respond objectively. Further, the complexity of the mediated model reduces the CMB threat as respondents are less likely to be guided by their cognitive map for complex models (Chang et al., 2010). Also, Siemsen, Roth and Oliveira (2010) demonstrated that "quadratic and interaction effects cannot be artefacts of CMB” (p.456) rather they can severely deflate such effects.

In addition, we used two statistical remedies: Harman's single factor test and Lindell and Whitney's marker variable technique. Unrotated exploratory factor analysis did not result in any of the constructs accounting for a majority of the covariance between the measures, thus satisfying the Harman (1976) single factor test. We also ran the whole model with and without a marker variable. The marker variable consisted of two items about Indian managers' rating on their agreement about New Zealand being a great place to live a good life. Significance levels of all the examined relationships stayed the same with very minor changes in standardised coefficient estimates. Even the interactive effaces of two CQ facets also stayed the same with some minor improvements in p values. This is in line with Siemsen et al. (2010) who showed that interaction effects are immune from CMB. Also, there was no increase in $\mathrm{R}^{2}$ value. Further, the marker variable had non-significant results with all of the endogenous 
variables and thus satisfied the marker variable test for CMB (Lindell and Whitney, 2001). Based on the used procedural and statistical remedies, and the complexity of the model, we can safely argue that the findings do not suffer from common method bias.

\section{Model estimation and results}

We test the proposed hypotheses using partial-least-square-based structural equation modelling (PLS-SEM). Hair et al. (2017) argue the PLS-SEM is an effective alternative when the goal is prediction or theory building, the structural model is complex, and data is non-normally distributed. The use of PLS-SEM is justified as the proposed model focuses on building theory by examining one of the mechanisms (RQ as a mediator) that transform the impact of CQ on institutional success; and the interactive effects (complex model) of two CQ facets. Both the conceptual and structural models are examined using SmartPLS 3 (Ringle, Wende and Becker, 2015). The results are obtained by running PLS algorithm, bootstrapping and blindfolding procedures.

The measurement model, as presented in Tables 2 and 3, satisfies the required reliability and validity criteria. Hair et al. (2017) summarise various benchmarks for reflective measurement models as composite reliability $\geq 0.70$ (internal consistency), factor loadings $\geq$ 0.70 (indicator reliability), average variance extracted (AVE) >0.50 (convergent validity), square root of the variance extracted of each construct $>$ any vertical or horizontal correlations (Fornell-larcker criterion - discriminant validity), HTMT ratios <0.90, and HTMT ratios confidence intervals do not include 1 (discriminant validity).

*Tables 2 and 3 about here*

It is evident from Table 2 that both Chronbach's alpha and composite reliability values are above 0.70 , thus ensuring internal consistency reliability of the constructs. The AVE values range between 0.59 and 0.85 indicating convergent validity of the constructs. All except three 
factor loadings are above the benchmark of 0.70: one item for motivational CQ (0.66) and two items for RQ $(0.66,0.68)$. Hair et al. (2017) argue that items with factor loadings between 0.40 and 0.70 can be kept if their deletion does not impact consistency reliability (p.114). Accordingly these items were kept in the constructs. The Fornell-Larcker criteria (Table 3) ensures that the constructs are truly distinct from each other. The square root of each construct's AVE (bold diagonal in Table 3) is greater than its correlation with any other construct. We also checked discriminant validity with hetrotrait-monotrait (HTMT) ratios. All the ratios are less than 0.90 and their confidence intervals do not include 1 which satisfies the discriminant validity criteria. For the sake of simplicity, HTMT values are not reported in Table 3. The low $(<5)$ variance inflated factor $(\mathrm{VIF})$ values suggest that multicollinearity is also not an issue for this model (Hair et al., 2017).

Results for $\mathrm{H} 1$ and $\mathrm{H} 2$ are presented in Figures 2 and 3, and Table 4. The values shown in Figure 2 for various paths are $\beta$ (standardised path coefficient) with the significance level in parentheses followed by $\mathrm{f}^{2}$ effect size. Values in parentheses in the ovals are $\mathrm{R}^{2}$, and $\mathrm{Q}^{2}$ values in this order. We find mixed support for $\mathrm{H} 1$ and $\mathrm{H} 2$. The interaction of cognitive and metacognitive CQs have a positive significant direct effect on RQ (Figure 2b) and a nonsignificant effect on institutional success (Figure 2a): thus H1a (i) is supported while H1b (i) is not. However, metacognitive CQ by itself had a direct significant effect on institutional success while cognitive CQ has a negative significant effect. A look at simple slope graphs (Figure 3b) tells us that the impact of cognitive CQ on RQ is positive when it is accompanied by higher metacognitive CQ and negative when metacognitive CQ is low. Moreover, the interactive effects of cognitive and metacognitive CQs on RQ are stronger $(\beta=0.298, p=$ 0.002 ) as compared to their individual effects (cognitive: $\beta=-0.078, p=0.002$, metacognitive: $\beta=0.074, p=0.251$ ). Further, both $\mathrm{H} 1 \mathrm{~b}(\mathrm{i})$ and (ii) are supported as motivational CQ has a significant positive direct effect on RQ (Figure 2b) and institutional success (Figure 2a). H1c 
(i) and (ii), which argued for the positive effects of behavioural CQ, are not supported. The findings suggest negative significant effects for institutional success and negative nonsignificant for RQ which is contrary to expectations.

As suggested by Zhao, Lynch Jr and Chen (2010), we classified mediation effects as complementary, competitive, indirect-only; and non-mediation effects as direct-only and noeffect. Mediation is complementary when both the direct and mediated effects are significant and point in the same direction; and competitive when they point in opposite directions. Indirect-only mediation exists when direct effects are not significant while indirect effects are. Similarly, if indirect effects are non-significant while direct effects are, it is direct-only nonmediation. If neither direct nor indirect effects are significant, then it is no-effect nonmediation.

$\mathrm{H} 2$ argued for the mediating role of RQ. This hypothesis is also partially supported (Table 4). We find direct-only mediation effects for motivational CQ, and complementary mediation effects for the interactive effects of cognitive and metacognitive CQ. After including the mediator, the direct effects of both motivational CQ and the interaction of cognitive and metacognitive CQ become weaker indicating the existence of mediation effects (Baron and Kenny, 1986). We did not find any mediation effects (direct-only non-mediation) for behavioural CQ. None of the control variables are found to have a significant positive effect on institutional success, though interestingly language was found to have negative (nonsignificant) effect on RQ.

* Figures 2 and 3, and Table 4 about here*

The $\mathrm{R}^{2}$ values of the full model (Figure $2 \mathrm{~b}$ ) show that the CQ variables explain $34 \%$ variation of RQ while along with RQ it explains $56 \%$ of variation of manager's success in managing institutional differences. The $\mathrm{Q}^{2}$ values, being greater than zero, suggest that the model has acceptable predictive validity (Geisser, 1975; Stone, 1974). The effect size $\mathrm{f}^{2}$ values 
of $0.02,0.15$ and 0.35 represent small, medium and large effect sizes (Cohen, 1988). The effect size values as shown in Figure $2 \mathrm{~b}$ show small to medium effect sizes for the significant relationships. These effect sizes show the strength and practical significance of the relationships as compared to statistical significance as represented by p values (Ellis, 2010).

\section{Discussion and conclusion}

To examine the mediating role of relationship quality in the association between CQ facets and institutional success, firstly we examined the direct effects of interaction of two CQ mental capabilities (cognitive and metacognitive CQs), motivational CQ and behavioural CQ on relationship quality and institutional success. Our hypotheses for the direct effects of motivational CQ on institutional success and relationship quality, and interaction of cognitive and metacognitive CQ on relationship quality are supported. We find support for the mediating role of relationship quality for the interaction of cognitive and metacognitive CQs (indirectonly mediation) and motivational CQ (complementary mediation). Contrary to expectations, the impact of behavioural CQ resulted in negative direct-only non-mediation effects.

\subsection{Theoretical implications}

The proposed model mainly draws insights from the institutional theory and the theory of multiple intelligences. The institutional theory insights help explain overcoming managerial bounded rationality in managing institutional challenges while operating in an institutionally distant country by leveraging relationships with business partners (Aharoni et al., 2011; Dyer and Singh, 1998; Zhou et al., 2014). On the other hand, the interactive effects of two CQ facets, namely cognitive and metacognitive CQs, are examined in light of the theory of multiple intelligences which posits the existence of multiple autonomous intelligences in individuals which influence their behaviour individually and collectively (Davis et al., 2011; Sternberg, 
1985). Chua and $\mathrm{Ng}$ (2017) also examined these interactive effects to study creativity in multicultural teams.

The first main finding suggests that relationship quality has an indirect-only mediation effect on the association between the interactive effect of cognitive and metacognitive CQs and institutional success. Thus cognitive CQ, when accompanied by metacognitive CQ, significantly results in enhancing the relationship quality with business partners which leads to institutional success. These indirect-only mediation effects imply that: 1) cognitive CQ results in enhanced relationship quality when accompanied by metacognitive CQ; and 2) these interactive effects are not enough by themselves to achieve institutional success, rather the success is achieved because they enhance relationship quality. In other words, relationship quality is a significant mediator in the association between these CQ facets' interactions and institutional success.

Cultural knowledge (cognitive CQ) enables the understanding of the norms, practices and conventions of the other institutional environment in which managers are operating. Thus managers with high cognitive CQ have a broader knowledge of the foreign institutional environment. However, this broader knowledge may not be enough by itself, rather it would need to be accompanied by cultural metacognition which allows managers to be aware of the context, control their thought processes, constant learning and adjust their behaviour which helps build relationships with the unlike ones (Brislin et al., 2006). This finding aligns with the findings of Chua and $\mathrm{Ng}$ (2017) who argued that it is not just how much you know (cognitive CQ), rather it is strategic thinking (metacognitive CQ) which, when accompanied by cultural knowledge, results in better outcomes.

The second major finding suggests that relationship quality has a complementary mediation effect on the association between motivational CQ and institutional success. It either implies that it has a direct as well as an indirect effect on institutional success or that there are 
additional mediators such as cultural adjustment (Chen et al., 2010). Individuals with higher motivational CQ are better able to adapt to other cultures and thus reduce anxiety of operating in unfamiliar institutional environments. As such individuals enjoy cross-cultural experiences in which they are better able to develop cross cultural relationships. Their intrinsic motivation and self-efficacy enables them to utilise mental capacity and energy for real life problem solving (Ceci, 1996). Such managers have an intrinsic interest and confidence in managing institutional differences effectively (Bandura, 2002). They are more adaptive to other cultures and enjoy working in culturally diverse settings (Ang et al., 2007; Peng et al., 2015).

The above two findings highlight the role of relational capital in managing uncertainty of the foreign institutional environments (Dyer and Singh, 1998; Peng et al., 2008; Zhou et al., 2014). Culturally intelligent managers are better able to build quality relationships as they have higher knowledge and understanding of their counterparts and have motivation (a can-do approach) to manage institutional challenges. The mediating role of relationship quality has also been established in other settings such as firm performance (Raman et al., 2013). Relationship quality along with cultural intelligence help manage the dark side of relationships (Anderson and Jap, 2005). Cognitive, metacognitive and motivational CQs facilitate knowledge of cultural norms and practices, contextualised thinking and cognitive flexibility, and intrinsic motivation and cultural self-efficacy. These help manage relationships and thus succeed in managing the institutional environmental differences. Ho et al. (2018) argue that regulatory and cognitive differences can be managed through good relationships with overseas business partners. Trusted relationships with effective communication and coordination allow common management approaches. Learning from these relationships helps to manage anxiety and uncertainty. There is higher anxiety and uncertainty while dealing with unfamiliar people and environments (Gudykunst, 2005). Culturally intelligent managers are able to manage this uncertainty well. 
Surprisingly and contrary to our expectations we find significant negative direct effects of behaviour CQs on institutional success and negative non-significant effects on relationship quality which resulted in a negative direct-only non-meditation relationship with institutional success. In their meta-analysis Rockstuhl and Van Dyne (2018) find a non-significant negative effect of behavioural CQ on intercultural adaptation. It appears that building close relationships relies more on cultural knowledge and understanding, and mental capacity to leverage energy in problem solving and ability to learn in diverse situations. We believe that the negative role of behavioural CQ may be because of the context of the study: managers from a non-native English speaking emerging economy dealing with managers from a native English speaking advanced economy. Behavioural CQ is measured by the ability to change verbal and nonverbal behaviour which may not be working for Indian managers. It is likely that there may be a gap in the Indian managers' perceived behavioural adaptability and New Zealand managers' expected behavioural adaptability.

Moreover New Zealand is a low context communication while India is a high context communication culture. Since behavioural CQ comprises of both verbal and non-verbal behaviours, it may be less relevant to communication adjustment in New Zealand. Zhang and Oczkowski (2016) found that behavioural CQ was important for the adjustment of Australian managers in China (going from low context to high context communication) but not for Chinese managers in Australia (going from high context to low context communication). To understand the role of behavioural CQ better, future research may be needed that employs the extended CQ scale (E-CQS) (Van Dyne et al., 2012) which includes the repertoire in speech acts as well.

Finally the negative effect, even though it is non-significant, of languages on relationship quality is also surprising. A close look at the data collected showed that the additional languages known by Indian managers are other Indian languages rather than 
international languages. It also indicates domestic exposure rather than international cultural exposure. This needs further examination as the role of language in international business has been well accepted (Tenzer, Terjesen and Harzing, 2017).

The role of relationships and cultural intelligence is critical for managerial decision making as managers rely on their perceptions and assessments which are boundedly rational. Full rationality rarely exists and such gaps in cognitive assessments and abilities can be filled up through relational capital (Aharoni et al., 2011). In unfamiliar environments, individuals' relationships and their mental abilities help them manage environmental uncertainties (Aharoni, 1966). There have been recent calls to understand the effects of cognitive attributes and interactions of cultural intelligence facets on a managerial outcome (Aharoni et al., 2011; Ott and Michailova, 2018; Rockstuhl and Van Dyne, 2018). Our study contributed to this discussion by examining the interactive effects of two related CQ facets (cognitive and metacognitive CQs), motivational $\mathrm{CQ}$ and behavioural $\mathrm{CQ}$ on relationship quality and institutional success, and the mediating role of relationship quality between CQ facets and institutional success. Though the literature talks about the role of relationships for operating in institutionally weaker countries (Peng et al., 2009), we find that it is equally relevant for mangers from institutionally weaker countries to operate effectively in institutionally stronger countries.

\subsection{Managerial implications}

The findings have some important implications for managers. First, we highlight the critical interactive role of both cognitive and metacognitive CQs in having quality relationships with business partners which result in succeeding in managing challenges arising out of institutional differences. Thus to build relationships it is not just how much you know about your business partner's culture, but it is also about having strategic thinking, deep understanding, higher level 
thinking, and higher intrinsic interest in their culture. We also identify the role of motivational CQ in building quality relationships and thus having institutional success. While cognitive and metacognitive CQs represent cultural knowledge and strategic higher level thinking, motivational CQ represents the 'can do' approach.

Earley and Mosakowski (2004) analogises cognitive CQ as 'Head', motivational CQ as 'Heart', and behavioural CQ as 'Body'. They argue that all the three are essential in leadership effectiveness, thus there is a need to examine each of these to know where training is needed for improvement. The current CQ conceptualisation (Ang et al., 2007) includes cognitive (cultural knowledge) and metacognitive CQs (higher level thinking) in addition to the other two. With reference to the given Head, Heart, and Body analogy; we believe that both the cognitive and metacognitive can be analogised as 'Head'. We find support for the role of 'Head' and 'Heart' in building relationships and having institutional success. Our findings, did not find support for the impact of 'Body' (behavioural CQ) in building relationships and managing institutional challenges.

Given our findings that motivational CQ and the interaction of cognitive and metacognitive CQs influence institutional success by enhancing relationship quality, and the evidence of the positive effect of CQ on global leadership effectiveness (Rockstuhl et al., 2011), managers need to consciously assess their CQ facets and attempt to strengthen the weaker ones. CQ can be enhanced by proper training and practice (Earley and Mosakowski, 2004; Hahn and Molinsky, 2018).

Secondly, investing in sustaining quality relationships with business partners is critical for managing institutional differences. Relationship quality also helps to enhance firm performance in general (Leonidou et al., 2014). Thus, relational capital is not just useful for advanced economy managers operating in emerging economies as put forward by Peng et al. 
(2008), it appears equally useful for emerging economy managers operating in advanced economies.

Finally, institutional differences pose challenges to managers. Managers operating in institutionally different environments face challenges of misunderstandings and legitimacy caused by the lack of shared cognitive and regulatory frameworks (Abdi and Aulakh, 2012; Denk et al., 2012). A conscious approach of enhancing 'Head' and Heart' CQ facets of the concerned managers and investing in building relationships is likely to help them to operate effectively in institutionally different environments.

\subsection{Limitations}

The findings need to be interpreted carefully and with caution in regard to generalisability. The data draws on the experience of Indian managers doing business with New Zealand. Ideally, the model should also be examined for the experience of New Zealand managers doing business with India. Moreover, a dyadic approach of examining data on both the sides is suggested for future studies. In particular, relationship quality being a dyadic construct should be measured with inputs from both sides. Though all efforts are undertaken to make sure that the survey is answered by an appropriate manager, ideally interview-based questionnaire surveys should replace the drop-and-pick method of data collection utilised in this study. Also additional control variables such as past firm performance and number of partners should be included by future researchers. Moreover, some CQ measurement items did not load to the constructs for our data. Further research may help clarify whether this is because of this specific survey, or because of the country context. Also, though the common method bias threat has been examined and it does not post threat to the findings, ideally the data on the dependent variable should be collected from a different source. 


\subsection{Conclusions}

Despite some limitations of the study, we have demonstrated some interesting findings. Our findings show that relationship quality is the mechanism through which cognitive CQ when accompanied by metacognitive CQ, and motivational CQ result in managing institutional differences. To summarise, both Head (cognitive accompanied by metacognitive CQs) and Heart (motivational CQ) result in good quality relationships and thus institutional success. Further investigations are needed to see whether the contradictory finding of negative effects of behavioural CQ (Body) is because of the context of the study and whether this can be generalised. 


\section{Figure 1: The Conceptual Model}

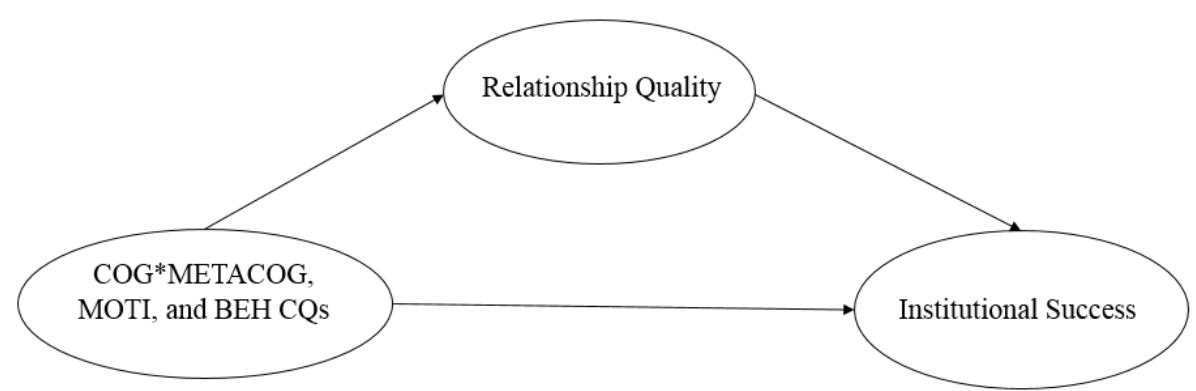

Note: COG, METACOG, MOTI and BEH CQs stand for cognitive, metacognitive, motivational and behavioural cultural intelligences while $*$ denotes interactive effects

Table 1: Sample Characteristics

\begin{tabular}{|c|c|}
\hline \multirow{2}{*}{\multicolumn{2}{|c|}{$\begin{array}{r}\text { Attributes } \\
\text { Age (Average } 43 \text { years) }\end{array}$}} \\
\hline & \\
\hline Up to 30 years & $6(11 \%)$ \\
\hline $31-40$ years & $58(31 \%)$ \\
\hline $41-50$ years & $70(38 \%)$ \\
\hline $51-60$ years & $30(16 \%)$ \\
\hline 61 years and above & $8(4 \%)$ \\
\hline \multicolumn{2}{|l|}{ Gender } \\
\hline Male & $176(95 \%)$ \\
\hline Female & $10(5 \%)$ \\
\hline \multicolumn{2}{|l|}{ Education } \\
\hline $\begin{array}{l}\text { Undergraduate } \\
\text { Postgraduate }\end{array}$ & $\begin{array}{l}55(30 \%) \\
131(70 \%)\end{array}$ \\
\hline \multicolumn{2}{|l|}{ Languages known (Average 3.12) } \\
\hline $1-2$ languages & $18(10 \%)$ \\
\hline 3 languages & $134(72 \%)$ \\
\hline $4-6$ languages & $34(18 \%)$ \\
\hline \multicolumn{2}{|l|}{$\begin{array}{l}\text { International Experience } \\
\text { (Average } 23.04 \text { years) }\end{array}$} \\
\hline Up to 10 years & $41(22 \%)$ \\
\hline $11-20$ years & $53(28 \%)$ \\
\hline $21-31$ years & $44(24 \%)$ \\
\hline $\begin{array}{l}31-40 \text { years } \\
41 \text { years and above }\end{array}$ & $\begin{array}{l}28(15 \%) \\
20(11 \%)\end{array}$ \\
\hline
\end{tabular}


Cognitive CQ ( $\alpha$ 0.905, Pc 0.939, AVE 0.837)

Select that best describes you as you really are

( 7 point Scale: 1 = Strongly disagree, $7=$ Strongly agree)

1. I know the cultural values and religious beliefs of other cultures

2. I know the marriage systems of other cultures

3. I know arts and crafts of other cultures

Metacognitive CQ ( $\alpha$ 0.908, Pc 0.932, AVE 0.775)

Select that best describes you as you really are

( 7 point Scale: 1 = Strongly disagree, 7 = Strongly agree)

1. I am conscious of the cultural knowledge I use when interacting with people with different cultural backgrounds

2. I adjust my cultural knowledge as I interact with people from a culture that is unfamiliar to me

3. I am conscious of the cultural knowledge I apply to cross-cultural interactions

4. I check the accuracy of my cultural knowledge as I interact with people from different cultures

0.868

Motivational CQ ( $\alpha$ 0.855, Pc 0.904, AVE 0.706)

Select that best describes you as you really are

( 7 point Scale: 1 = Strongly disagree, 7 = Strongly agree)

1. I am confident that I can socialize with locals in a culture that is unfamiliar to me

2. I am sure I can deal with the stress of adjusting to a culture that is new to me

3. I enjoy living in cultures that are unfamiliar to me

4. I am confident that I can get accustomed to the shopping conditions in a different culture

Behavioural CQ ( $\alpha$ 0.882, Pc 0.926, AVE 0.807)

Select that best describes you as you really are

( 7 point Scale: 1 = Strongly disagree, 7 = Strongly agree)

1. I change my verbal behaviour when (e.g. accent, tone) when a cross cultural interaction requires it

2. I vary the rate of my speaking when a cross cultural situation requires it

Relationship Quality (RQ): $\alpha$ 0.843, Pc 0.878, AVE 0.593

Relationships with your local business partner

( 7 point Scale: 1 = Strongly disagree, 7 = Strongly agree)

1. Respect for local business partner

2. Quick problem solving

3. Regular interactions

4. Long term relationship

5. Overall partner satisfaction

Institutional Success ( $\alpha$ 0.957, Pc 0.966, AVE 0.852)

Success in managing institutional differences

( 7 point Scale: 1 = Extremely unsuccessful , $7=$ Extremely successful)

1. Nature of rules, laws and regulations

2. Enforcement of rules, laws and regulations

3. Cultural values, beliefs and norms

4. Ethical business practices 
Table 3. Discriminant Validity and Correlations

\begin{tabular}{|l|l|c|l|l|l|l|l|l|l|l|l|l|}
\hline & & VIF & 1 & 2 & 3 & 4 & 5 & 6 & 7 & 8 & 9 & 10 \\
\hline 1 & Institutional Success & -- & $\mathbf{0 . 9 2 3}$ & & & & & & & & & \\
\hline 2 & Cognitive CQ & 1.179 & -0.165 & $\mathbf{0 . 9 1 5}$ & & & & & & & \\
\hline 3 & Metacognitive CQ & 1.169 & 0.241 & 0.063 & $\mathbf{0 . 8 8 0}$ & & & & & & & \\
\hline 4 & Motivational CQ & 1.495 & 0.590 & 0.109 & 0.222 & $\mathbf{0 . 8 4 0}$ & & & & & & \\
\hline 5 & Behavioural CQ & 1.317 & -0.088 & 0.365 & 0.283 & 0.242 & $\mathbf{0 . 8 9 8}$ & & & & & \\
\hline 6 & Relationship Quality & 1.493 & 0.574 & 0.058 & 0.179 & 0.534 & 0.206 & $\mathbf{0 . 7 7 0}$ & & & & \\
\hline 7 & Age & 1.095 & 0.011 & 0.077 & -0.32 & 0.034 & -0.003 & -0.017 & 1 & & & \\
\hline 8 & Education & 1.061 & -0.046 & -0.015 & -0.129 & -0.055 & -0.126 & -0.030 & -0.079 & 1 & & \\
\hline 9 & Languages & 1.124 & -0.086 & 0.099 & 0.174 & 0.004 & 0.128 & -0.126 & 0.064 & -0.179 & 1 & \\
\hline 10 & International Experience & 1.117 & -0.023 & -0.062 & -0.098 & 0.064 & -0.054 & -0.086 & 0.253 & 0.041 & -0.077 & 1 \\
\hline Notes: CQ = Cultural Intelligence, VIF = Variance Inflated Factor & & & & & \\
\hline
\end{tabular}




\section{Figure 2: Results}

Figure 2a: Direct effects of cultural intelligence

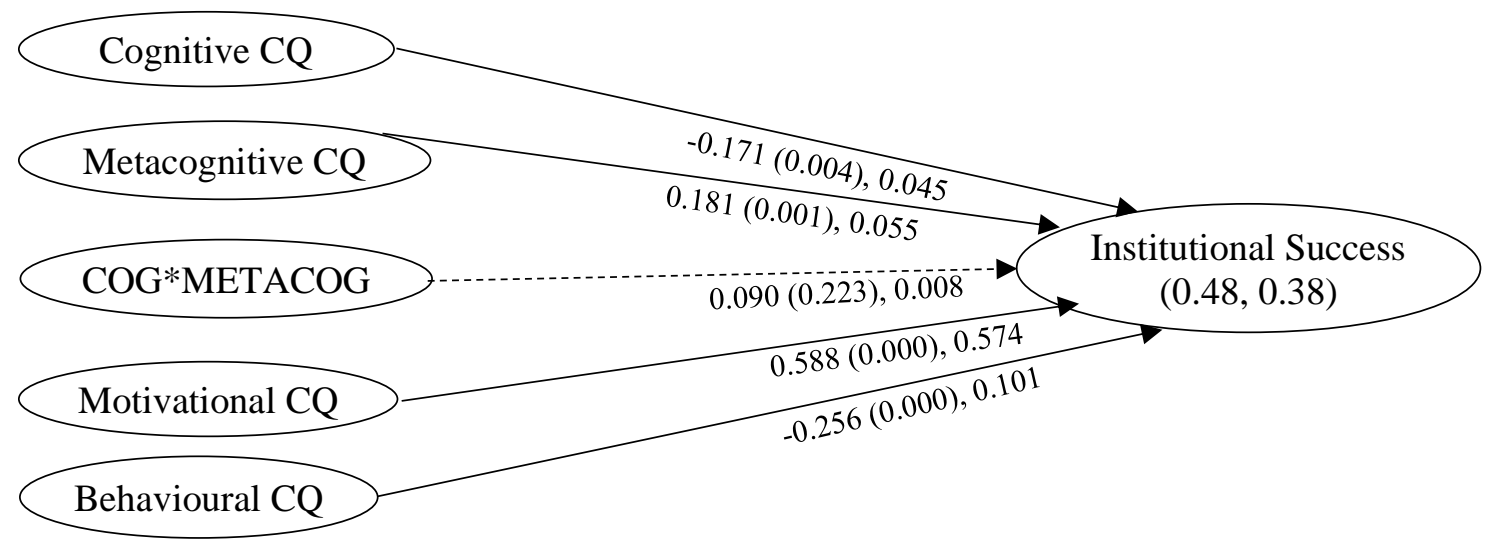

Figure 2b: Mediating effects of relationship quality

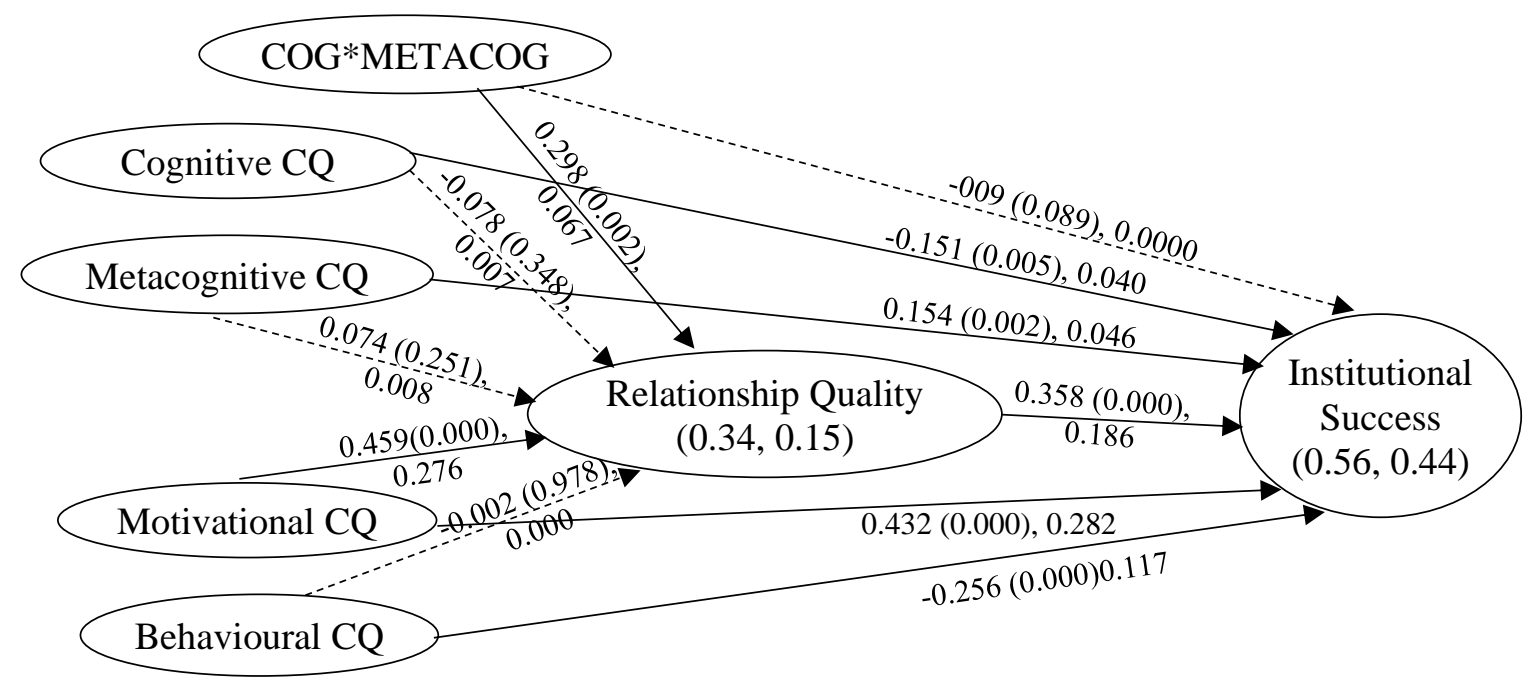

Notes: Values shown for various paths are $\beta$ (standardised path coefficient) with significance level in parentheses followed by $\mathrm{f}^{2}$ effect size. Values in parentheses in the ovals are $\mathrm{R}^{2}$, and $\mathrm{Q}^{2}$ values in this order. CQ stands for cultural intelligence. For interactive effects, cognitive and metacognitive CQs are denoted as COG and METACOG respectively. 
Figures 3: Interactive Effects of Cognitive and metacognitive cultural intelligence

3a)

Interactive effects on institutioanl success

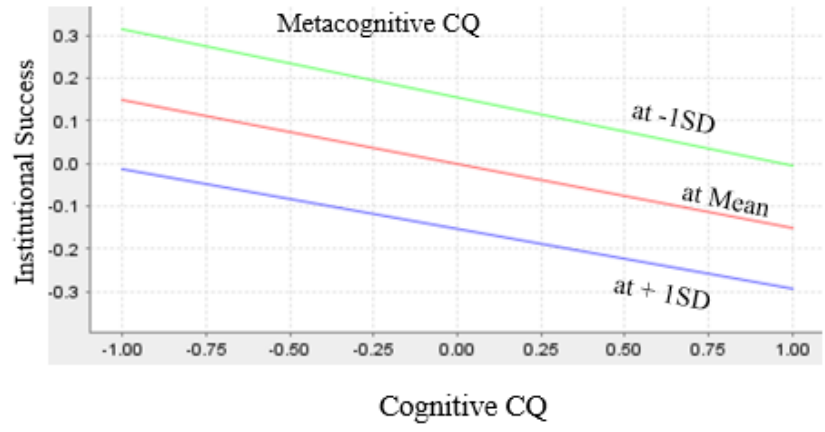

3a)

Interactive effects on relationship quality

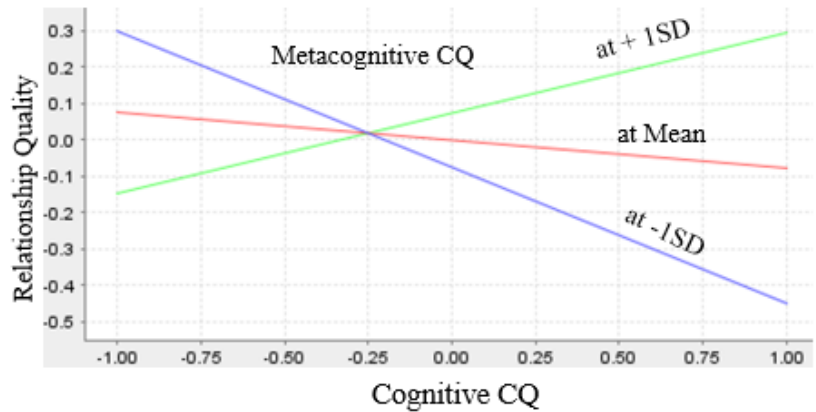

Table 4. Analysis of Specific Indirect Effects

\begin{tabular}{|l|l|l|l|c|c|c|l|}
\hline No & \multicolumn{1}{|c|}{ Path } & $\begin{array}{c}\text { Indirect } \\
\text { Effect }\end{array}$ & $\begin{array}{c}\text { Standard } \\
\text { Error }\end{array}$ & $\begin{array}{c}\mathrm{T} \\
\text { Value }\end{array}$ & $\begin{array}{c}\text { P } \\
\text { Value }\end{array}$ & $\begin{array}{c}\text { Confidence } \\
\text { Interval 95\% }\end{array}$ & \multicolumn{1}{|c|}{$\begin{array}{c}\text { Mediation } \\
\text { Effect }\end{array}$} \\
\hline 1 & COG $\rightarrow$ RQ $\rightarrow$ IS & -0.028 & 0.031 & 0.903 & 0.367 & $-0.099-0.025$ & $\begin{array}{l}\text { Direct-only } \\
\text { non-mediation }\end{array}$ \\
\hline 2 & METACOG $\rightarrow$ RQ $\rightarrow$ IS & 0.027 & 0.024 & 1.104 & 0.270 & $-0.019-0.075$ & $\begin{array}{l}\text { Direct-only } \\
\text { non-mediation }\end{array}$ \\
\hline 3 & COG*METACOG $\rightarrow$ RQ $\rightarrow$ IS & 0.107 & 0.041 & 2.619 & 0.009 & $0.039-0.202$ & $\begin{array}{l}\text { Indirect-only } \\
\text { mediation }\end{array}$ \\
\hline 4 & MOTI $\rightarrow$ RQ $\rightarrow$ IS & 0.164 & 0.034 & 4.861 & 0.000 & $0.108-0.241$ & $\begin{array}{l}\text { Complementar } \\
\text { y mediation }\end{array}$ \\
\hline 5 & BEH $\rightarrow$ RQ $\rightarrow$ IS & -0.001 & 0.028 & 0.027 & 0.978 & $-0.054-0.055$ & $\begin{array}{l}\text { Direct-only } \\
\text { non-mediation }\end{array}$ \\
\hline $\begin{array}{l}\text { Notes: } \\
\text { 1. Cognitive, metacognitive, motivational and behavioural CQs are denoted as COG, METACOG, MOTI and BEH respectively. } \\
\text { 2. Relationship quality and institutional success are denoted as RQ and IS respectively. } \\
\text { 3. Confidence intervals are bias corrected confidence intervals. }\end{array}$
\end{tabular}




\section{References}

Abdi, M., Aulakh, P.S., 2012. Do country level institutional frameworks and interfirm governance arrangements substitute or complement in international business relationships. Journal of International and Area Studies 43, 477-497.

Aharoni, Y., 1966. The Foreign Investment Decision Process. Harvard Business School Press, Boston, MA.

Aharoni, Y., Tihanyi, L., Connelly, B.L., 2011. Managerial decision-making in international business: A forty-five-year retrospective. Journal of World Business 46, 135-142.

Anderson, E., Jap, S.D., 2005. The dark side of close relationships. MIT Sloan Management Review 46, 75-82.

Andresen, M., Bergdolt, F., 2017. A systematic literature review on the definitions of global mindset and cultural intelligence - merging two different research streams. International Journal of Human Resource Management 28, 170-195.

Ang, S., Van Dyne, L., Koh, C., Ng, K.Y., Templer, K.J., Tay, C., Chandrasekar, N.A., 2007. Cultural intelligence: Its measurement and effects on cultural judgment and decision making, cultural adaptation and task performance. Management \& Organization Review 3, 335-371.

Ashkenas, R., Ulrich, D., Jick, J., Kerr, S., 2002. The Boundaryless Organization: Breaking the Chains of Organizational Structure. Jossey-Bass, San Francisco, CA.

Bandura, A., 2002. Social cognitive theory in cultural context. Applied Psychology: An International Review 51, 269-290.

Baron, R.M., Kenny, D.A., 1986. The moderator-mediator variable distinction in social psychological research: Conceptual, strategic, and statistical considerations. Journal of Personality and Social Psychology 51, 1173.

Bernerth, J.B., Aguinis, H., 2016. A critical review and best-practice recommendations for control variable usage. Personnel Psychology 69, 229-283.

Bird, A., Mendenhall, M., Stevens, M.J., Oddou, G., 2010. Defining the content domain of intercultural competence for global leaders. Journal of Managerial Psychology 25, 810-828.

Brislin, R., Worthley, R., Macnab, B., 2006. Cultural intelligence: Understanding behaviours that serve people's goals. Group and Organizational Management 31, 40-55.

Bücker, J.J.L.E., Furrer, O., Poutsma, E., Buyens, D., 2014. The impact of cultural intelligence on communication effectiveness, job satisfaction and anxiety for Chinese host country managers working for foreign multinationals. International Journal of Human Resource Management 25, 2068-2087.

Ceci, S.J., 1996. On Intelligence: A Bioecological Treatise on Intellectual Development. Harvard University Press, Cambridge, Mass.

Chang, S.-J., Witteloostuijn, A.v., Eden, L., 2010. From the editors: Common method variance in international business research. Journal of International Business Studies 41, 178-184.

Chen, G., Kirkman, B.L., Kim, K., Farh, C.I.C., Tangirala, S., 2010. When does cross-cultural motivation enhance expatriate effectiveness? A multilevel investigation of the moderating roles of subsdiary support and cultura distance. Academy of Management Journal 53, 1110-1130.

Chua, R.Y.J., Morris, M.W., Mor, S., 2012. Collaborating across cultures: Cultural metacognition and affect-based trust in creative collaboration. Organizational Behavior \& Human Decision Processes 118, 116-131.

Chua, R.Y.J., Ng, K.Y., 2017. Not just how much you know: Interactional effect of cultural knowledge and metacognition on creativity in a global context. Management \& Organization Review 13, 281-300. Cohen, J., 1988. Statistical Power Analysis for the Behavioral Sciencies. Routledge.

CPI, 2014. Corruption Perception Index. Transparency International, Berlin, Germany.

Crowne, K.A., 2013. Cultural exposure, emotional intelligence, and cultural intelligence: An exploratory study. International Journal of Cross Cultural Management 13, 5-22.

Davis, K., Christodoulou, J., Seider, S., Gardner, H., 2011. The theory of multiple intelligencies, in: Sternberg, R.J., Kaufman, S.B. (Eds.), Cambridge Handbook of Intelligence. Cambridge University Press, Cambridge, U.K.; New York, pp. 485 - 503.

Deal, J.J., Leslie, J., Dalton, M., Ernst, C., 2001. Cultural adaptability and leading across cultures., in: Mobley, W.H., Dorfman, P.W. (Eds.), Advances in Global Leadership JAI Press, Oxford, pp. 149-166. 
Denk, N., Kaufmann, L., Roesch, J.-F., 2012. Liabilities of foreignness revisited: A review of contemporary studies and recommendations for future research. Journal of International Management $18,322-334$.

Doz, Y., Santos, J., Williamson, P.J., 2001. From Global to Metanational: How Companies Win in the Knowledge Economy. Harvard Business Press, Boston, M.A.

Dyer, J.H., Singh, H., 1998. The relational view: Cooperative strategy and sources of interorganizational competitive advantage. The Academy of Management Review 23, 660-679.

Earley, C.P., Ang, S., 2003. Cultural intelligence: Individual interactions across cultures. Stanford University Press, Stanford, CA.

Earley, P.C., Mosakowski, E., 2004. Cultural Intelligence. Harvard Business Review 82, 139-146.

Elfenbein, D.W., Zenger, T.R., 2014. What is a relationship worth? Repeated exchange and the development and deployment of relational capital. Organization Science 25, 222-244.

Ellis, P., 2010. Effect sizes and the interpretation of research results in international business. Journal of International Business Studies 41, 1581-1588.

Enlow, S., Ertel, D., 2006. Achieving outsourcing success: Effective relationship management. Compensation \& Benefits Review 38, 50-55.

Fitch, K., 1998. Speaking Relationally: Culture, Communication and Interpersonal Connection. Guildford Press, New York.

Geisser, S., 1975. The predictive sample reuse method with applications. Journal of the American Statistical Association 70, 320-328.

Gelfand, M.J., Imai, L., Fehr, R., 2008. Thinking intelligently about cultural intelligence: The road ahead, in: Dyne, S.A.L.V. (Ed.), handbook of Cultural Intelligence. M.E. Sharpe, New York, pp. 375387.

Groves, K.S., Feyerherm, A., Gu, M., 2015. Examining cultural intelligence and cross-cultural negotiation effectiveness. Journal of Management Education 39, 209-243.

Gudykunst, W.B., 2005. An anxiety/uncertainty management (AUM) theory of strangers' intercultural adjustment training, Theorising About Intercultural Communication. Thousand Oaks, CA: Sage.

Hahn, M., Molinsky, A., 2018. How to recover from a cultural faux pas. Harvard Business Review Digital Articles, 2-5.

Hair, J.F., Hult, G.T.M., Ringle, C.M., Sarstedt, M., 2017. A Primer on Partial Least Squares Structural Equations Modelling (PLS-SEM), 2e ed. SAGE Publications, California.

Harman, H.H., 1976. Modern Factor Analysis. University of Chicago, Chicago IL.

Henisz, W., Swaminathan, A., 2008. Institutions and international business. Journal of International Business Studies 39, 537-539.

Ho, M.H.-W., Ghauri, P.N., Larimo, J.A., 2018. Institutional distance and knowledge acquisition in international buyer-supplier relationships: The moderating role of trust. Asia Pacific Journal of Management 35, 427-447.

Hofstede, G., Hofstede, G.J., Mincov, M., 2010. Cultures and Organizations: Software of the Mind. Revised and Expanded 3rd ed. McGraw-Hill USA, New York.

Hutchings, K., 2003. Cross-cultural preparation of Australian expatriates in organisations in China: The need for greater attention to training. Asia Pacific Journal of Management 20, 375-396.

Ibeh, K., Brock, J.K.-U., Zhou, Y.J., 2004. The drop and collect survey among industrial populations: theory and empirical evidence. Industrial Marketing Management 33, 155-165.

Jiang, Z., Shiu, E., Henneberg, S., Naude, P., 2016. Relationship quality in business to business relationships: Reviewing the current literatures and proposing a new measurement model. Psychology \& Marketing 33, 297-313.

Kaufmann, D., Kraay, A., Mastruzzi, M., 2015. The Worldwide Governance Indicators. The World Bank.

Kim, Y.J., Van Dyne, L., 2012. Cultural intelligence and international leadership potential: The importance of contact for members of the majority. Applied Psychology: An International Review 61, 272-294.

Kostova, T., Roth, K., Dacin, M.T., 2008. Institutional theory in the study of multinational corporartions: A critique and new directions. Academy of Management Review 33, 994-1006.

Lages, C., Lages, C.R., Lagesc, L.F., 2005. The RELQUAL scale: A measure of relationship quality in export market ventures. Journal of Business Research 58, 1040-1048. 
Lages, L.F., Lancastre, A., Lages, C., 2008. The B2B-RELPERF scale and scorecard: Bringing relationship marketing theory into business-to-business practice. Industrial Marketing Management 37, 686-697.

Lahiri, S., Kedia, B.L., 2011. Determining quality of business-to-business relationships: A study of Indian IT-enabled service providers. European Management Journal 29, 11-24.

Leonidou, L.C., Samiee, S., Aykol, B., Talias, M.A., 2014. Antecedents and outcomes of exporterimporter relationship quality: Synthesis, meta-analysis, and directions for further research. Journal of International Marketing 22, 21-46.

Lindell, M.K., Whitney, D.J., 2001. Accounting for common method variance in cross-sectional research designs. Journal of applied psychology 86, 114-121.

Malek, M.A., Budhwar, P., 2013. Cultural intelligence as a predictor of expatriate adjustment and performance in Malaysia. Journal of World Business 48, 222-231.

Manning, T.T., 2003. Leadership across cultures: Attachment style influences. Journal of Leadership \& Organizational Studies 9, 20-32.

Mor, S., Morris, M., Joh, J., 2013. Identifying and training adaptive cross-cultural management skills: The crucial role of cultural metacognition. Academy of Management Learning \& Education 12, 453475 .

Ng, K.Y., Can Dyne, L., Ang, S., 2009. From experience to experential learning: Cultural intelligence as a learning capability for global leader development. Academy of Management Learning \& Education 8.

Ng, K.Y., Earley, C.P., 2006. Culture and intelligence: Old constructs, new frontiers. Group \& Organization Management 31, 4-19.

North, D.C., 1990. Instituitions, Institutioanl Change and Economic Performance. Harvard University Press, Cambridge, MA.

Osland, J.S., Bird, A., 2000. Beyond sophisticated stereotyping: Cultural sensemaking in context. Academy of Management Executive 14, 65-77.

Ott, D.L., Michailova, S., 2018. Cultural intelligence: A review and new research avenues. International Journal of Management Reviews 20, 99-119.

Peng, A.C., Van Dyne, L., Oh, K., 2015. The influence of motivational cultural intelligence on cultural effectiveness based on study abroad. Journal of Management Education 39, 572-596.

Peng, M.W., 2002. Towards an institution-based view of business strategy. Asia Pacific Journal of Management 19, 251.

Peng, M.W., Sunny Li, S., Pinkham, B., Hao, C., 2009. The institution-based view as a third leg for a strategy tripod. Academy of Management Perspectives 23, 63-81.

Peng, M.W., Wang, D.Y.L., Jiang, Y., 2008. An institution-based view of international business strategy: A focus on emerging economies. Journal of International Business Studies 39, 920-936.

Podsakoff, P.M., macKenzie, S.B., Lee, J.-Y., 2003. Common method bias in behavioral research: A critical review of the literature and recommended remedies. Journal of applied psychology 88, 879-903. Raman, R., Chadee, D., Roxas, B., Michailova, S., 2013. Effects of partnership quality, talent management, and global mindset on performance of offshore IT service providers in India. Journal of International Management 19, 333-346.

Ringle, C.M., Wende, S., Becker, J.-M., 2015. SmartPLS 3. Boenningstedt: SmartPLS GmbH, http://www.smartpls.com.

Rockstuhl, T., Seiler, S., Ang, S., Dyne, L.V., Annen, H., 2011. Beyond general intelligence (IQ) and emotional intelligence (EQ): The role of cultural intelligence (CQ) on cross border leadership effectiveness in a globalized world. Journal of Social Issues 67, 825-840.

Rockstuhl, T., Van Dyne, L., 2018. A bi-factor theory of the four-factor model of cultural intelligence: Meta-analysis and theoretical extensions. Organizational Behavior \& Human Decision Processes 148, 124-144.

Rosen, R.H., Digh, P., Phillips, C., Rosen, R.T., 2000. Global literacies: Lessons on business leadership and national cultures. Simon and Schuster, New York.

Salovey, P., Mayer, J.D., 1990. Emotional intelligence. Imagination, Cognition, and Personality 9, 185 211. 
Schlägel, C., Sarstedt, M., 2016. Assessing the measurement invariance of the four-dimensional cultural intelligence scale across countries: A composite model approach. European Management Journal 34, 633-649.

Schmidt, F.L., Hunter, J.E., 2000. Select on intelligence, in: Locke, E.A. (Ed.), The Blackwell handbook of organizational principles. Blackwell, Oxford, pp. 3-14.

Shaffer, M.A., Harrison, D.A., Gregersen, H., Black, J.S., Ferzandi, L.A., 2006. You can take it with you: Individual differences and expatriate effecetiveness. Journal of applied psychology 91, 109-125.

Sharma, R.R., Chadee, D., Roxas, B., 2016. Effects of knowledge management on client-vendor relationship quality: The mediating role of global mindset. Journal of Knowledge Management 20, 1268-1281.

Siemsen, E., Roth, A., Oliveira, P., 2010. Common method bias in regression models with linear, quadratic, and interaction effects. Organizational Research Methods 13, 456-476.

Sternberg, R.J., 1985. Beyond IQ: A Triarchic Theory of Human Intelligence. Cambridge University Press, Cambridhe, England.

Stone, M., 1974. Cross-validatory choice and assessment of statistical predictions. Journal of the Royal Statistical Society 36, 111-147.

Tajfel, H., 1981. Human Groups and Social Categories. Cambridge University Press, Cambridge, England.

Templer, K.J., Tay, C., Chandrasekar, N.A., 2006. Motivational cultural intelligence, realistic job preview, realistic living conditions preview, and cross- cultural adjustment. Group \& Organization Management 31, 154-173.

Tenzer, H., Terjesen, S., Harzing, A.-W., 2017. Language in international business: A review and agenda for future research. Management International Review 57, 815-854.

Thomas, D.C., 2017. Measuring cultural intelligence: Implications and opportunities. Rutgers Business Review 2, 205-211.

Thomas, D.C., Elron, E., Stahl, G., Ekelund, B.Z., Ravlin, E.C., Cerdin, J.-L., Poelmans, S., Brislin, R., Pekerti, A., Aycan, Z., Maznevski, M., Au, K., Lazarova, M.B., 2008. Cultural intelligence: Domain and assessment. International Journal of Cross Cultural Management : CCM 8, 123.

Thomas, D.C., Liao, Y., Aycan, Z., Cerdin, J.-L., Pekerti, A.A., Ravlin, E.C., Stahl, G.K., Lazarova, M.B., Fock, H., Arli, D., Moeller, M., Okimoto, T.G., van de Vijver, F., 2015. Cultural intelligence: A theory-based, short form measure. Journal of International Business Studies 46, 1099-1118.

Trąpczyński, P., Banalieva, E.R., 2016. Institutional difference, organizational experience, and foreign affiliate performance: Evidence from Polish firms. Journal of World Business 51, 826-842.

Triandis, H.C., 2006. Cultural intelligence in organizations. Group \& Organization Management 31, 20-26.

Turner, J.C., 1987. Rediscovering the Social Group: A Self-categorization Theory. Basil Blackwell, Oxford.

UNDP, 2014. Human Development Report 2014. Sustaining Human Reosurces - Reducing Vulnerabilities and Building Resilience. United Nations Development Programme, New York, USA.

Van Dyne, L., Ang, S., Ng, K.Y., Rockstuhl, T., Tan, M.L., Koh, C., 2012. Sub-dimensions of the four factor modell of cultural intelligence: Expanding the conceptualization and measurement of cultural intelligence. Social and Personality Psychology Compass 6, 295-313.

Van Hoorn, A., Maseland, R., 2016. How institutions matter for international business: Institutional distance effects vs institutional profile effects. Journal of International Business Studies 47, 374-381.

WorldBank, 2014. Doing Business 2015: Going Beyond Efficiency, 12th ed. World Bank. DOI: 10.1596/978-1-4648-0351-2. License: Creative Commons Attribution CC BY 3.0 IGO, Washington, DC.

Yu, Y., Sharma, R.R., 2016. Dancing with the stars: What do foreign firms get from high-status local partners? Management Decision 54, 1294-1319.

Zhao, X., Lynch Jr, J.G., Chen, Q., 2010. Reconsidering Baron and Kenny: Myths and truths about mediation analysis. Journal of Consumer Research 37, 197-206.

Zhang, Y., Oczkowski, E., 2016. Exploring the potential effects of expatriate adjustment direction. Cross Cultural \& Strategic Management 23, 158-183.

Zhou, K.Z., Zhang, Q., Sheng, S., Xie, E., Bao, Y., 2014. Are relational ties always good for knowledge acquisition? Buyer-supplier exchanges in China. Journal of Operations Management 32, 88-98. 